\title{
A Micromechanics Based Finite Element Model for the Prediction of Compressive Failure in Notched Laminated Composites
}

\author{
Junghyun $A n^{1}$ and Anthony M Waas ${ }^{2}$ \\ Composite Structures Laboratory \\ Department of Aerospace Engineering, \\ University of Michigan, Ann Arbor, MI 48109-2140
}

\begin{abstract}
A micromechanics based analysis to predict damage initiation in compressively loaded symmetric notched multiply laminates at elevated temperature under remote biaxial loading is described. The finite element method in conjunction with the commercial code $A B A Q U S^{\circledR}$ is used to solve the governing system of equations. The results obtained for the predictions are compared against a set of experimental results. A unified model that captures damage initiation and which describes failure mode by tracking the response of each lamina is presented. The prediction of the model is found to compare favorably against the experimental data.
\end{abstract}

\section{Introduction}

Laminated fiber reinforced polymer matrix composites (PMC's) are finding increased use in a broad range of industrial applications. Applications in the national infrastructure (such as allcomposite bridges over interstate highways), the automotive industry, medical, and the aerospace industry are some examples of where these materials are earmarked for several uses.

Composite materials are superior to conventional monolithic materials for a number of reasons, noteworthy amongst these being their mechanical properties. Ashby and Jones [(1994)] ${ }^{1}$ have formulated performance indices that can be used to select a material for a given application based on satisfying certain objective measures. PMC's appear to be the material of choice for a number of such applications. Issues such as damage tolerance and durability, performance degradation due to ageing, fatigue under multiaxial loads and response at elevated temperature are currently being researched with a view to expanding the confidence levels associated with PMC applications.

Experience with previous applications of PMC's for rotor blades in the helicopter industry, pressure vessels, and other similar situations that call for superior tensile stiffness and tensile fatigue life have shown the superior performance of PMC's in a tensile environment. In contrast, compressive strength of PMC's is known to be less attractive [Mathews and Rawlings, (1994)] ${ }^{2}$, [Waas and Schultheisz, (1995)] $]^{3}$.

The response of composite laminates when subjected to mechanical loads is influenced by the material type (fiber and matrix) and configuration (stacking sequence, lay-up). In addition to these factors, geometrical parameters (cut-out, notch, thickness change, etc.) and loading characteristics (multiaxial, thermal, cyclic loading, etc) also affect the overall performance of composite laminates. One of the challenging tasks in the analysis and design with PMC based structural laminates is to improve the predictive capability of the mechanical response of a composite structure that contains a discontinuity in the form of a cutout [Starnes et al.,

\footnotetext{
${ }^{1}$ Research Fellow, Aerospace Engineering, University of Michigan, Ann Arbor, member, AlAA. Copyright $(\mathbb{2} 2001$ by Junghyun Ahn, published by the American Institute of Aeronautics and Astronautics, Inc; with permission

${ }^{2}$ Professor of Aerospace Engineering, Associate Fellow, AIAA.
} 
(1979)] $]^{4}$ or a sudden thickness discontinuity such as the termination of reinforcement, under various design environments (loading, temperature, moisture, etc.).

Of concern in the present paper is the development of a micromechanics based model to predict the onset of failure in laminated composite plates containing a stress raiser in the form of a circular hole under multiaxial loading at room and elevated temperature. Both material degradation (due to temperature) and stress concentration effects were included in the analysis. The development of the model relies on previous experimental work reported by the authors [Ahn and Waas, (2001)] $]^{5}$. The predictions of the model are found to be in good agreement with the results reported in [Ahn and Waas, (2001)] .

\section{Modeling of Compressive Response of a Multiply Multidirectional Laminate}

As shown in a companion paper [Ahn and Waas, (2001) $]^{5}$, when a multidirectional laminate containing a circular hole is subjected to remote compressive loads, failure in the form of a microstructural instability is initiated in the vicinity of the hole, which is the area of highest stress concentration. For cross-ply laminates, the failure is triggered by 0 -degree ply instability, characterized by fiber kinking. For the case of quasi-isotropic laminates, which consist of zero and 45-degree plies, two types of failure mechanisms compete against each other. These are failure initiation due to fiber instability in the zero plies and failure initiated by matrix shear response, responsible for interface (fiber/matrix) cracking and/or shear failure in the 45 degree plies.

The dominant failure mode for this type of laminates has been reported as zero ply kinking failure [Ahn and Waas (1999)] $]^{6}$. However, it is not clear whether post mortem investigation or surface imaging of a particular laminate system (fiber, matrix, lay-up) can pinpoint the general failure initiation mechanism. Based on these facts, it was decided to investigate both possibilities of fiber kinking and matrix shear failure. Furthermore, it is hypothesized that the in-plane failure mode is the dominant mode of failure for the symmetric quasiisotropic laminates. These assumptions are discussed in more detail in [Ahn and Waas, 2000)] $]^{5}$.

The cross-ply laminates (Figure 1) were studied first, followed by the quasi-isotropic laminates (Figure 2). Unlike the cross-ply laminates $\left(0^{\circ}\right.$ and $90^{\circ}$ plies), the quasi-isotropic laminates have three kinds of lamina $\left(0^{\circ}, 45^{\circ}\right.$, and $90^{\circ}$ plies). Therefore, it is necessary to separate the two families of lamina in the region of study (the $0^{\circ} / 90^{\circ}$ lamina and the $45^{\circ}$ lamina).

The failure initiation analysis based on micromechanics is carried out in a manner similar to that described in [Ahn and Waas, (1999)] $]^{6}$. The region of failure near the cutout and corresponding to the zero plies are isolated and analyzed using the finite element method. The size of this region is left as an unknown of the problem. A converged solution is obtained when the salient features of the micromechanics based analysis shows no difference with respect to the size of the area meshed.

For the FEA analysis, a rectangular mesh containing 22,650 elements ( 4 node quadrilateral plane strain) and 23,028 nodes, with two degrees of freedom ( $u$ and $v$ ) per node was chosen. The $A B A Q U S \otimes$ commercial solver was used. The initial mesh size (termed "baseline model") corresponds to a rectangular region that is 300 fiber diameters $\left(d_{f}\right)$ in length and 142 fiber diameters in width. The elements were of length 2 $d_{f}$, and width $0.5 d_{f}$, such that two layers of elements constitute a single fiber. The matrix was also modeled with two adjacent elements, albeit the two matrix elements differed in width from the two fiber elements, taking into account the difference in thickness of the matrix such that the fiber volume fraction $\left(V_{f}\right)$, corresponds to the specimen (55\%). Convergence and mesh size dependency was checked by incrementally increasing the mesh size until no substantial change in the salient features (and values) associated with the response resulted. The results of the mesh sensitivity study are shown in Figure 4 and Table 4 for a configuration of the current analysis (hole diameter 0.5 in.). As can be seen in Table 4, the maximum limit load (our analysis uses this value as the failure initiation point) is insensitive to mesh size, and the plateau load also shows insignificant change as mesh size varies. Based on this mesh sensitivity study, the analysis model was deemed to have satisfactory convergence for the present study.

Each microregion is situated as shown shaded in Figure 1 and Figure 2, where the symmetry plane $(y=0)$ is marked as indicated. The Lekhnitskii's orthotropic, elasticity [Lekhnitskii, $(1968)]^{7}$ solution is used to compute the displacement fields along the edges corresponding to the microregion. These 
displacement fields are computed corresponding to a unit far-field load in the case of uniaxial loading and unit far-field proportional loads in the case of biaxial loading. Along the bottom edge of the microregion (marked as AD), equilibrium nodal equivalent loads are enforced. That is, the edge $A D$ is under load control, and the remaining edges are under displacement control, so that fibers can deform according to the requirement of far-field equilibrium. It turns out that, if an analysis is conducted with the edge $A D$ free of tractions, the results obtained for the salient features associated with the deformations within this microregion do not change. This is not surprising since the dominant loading is compression along the fibers, whereas the tractions along the bottom edge (edge $A D$ ) of the microregion are negligible compared to these dominant compressive stresses. Nevertheless, the objective is to obtain the limit load that the microregion can sustain and the corresponding far field stresses.

A flow chart of the analysis procedure is indicated in Figure 3(a). First, an elastic eigenvalue analysis of the microregion is carried out in order to obtain the eigenmodes of the microregion. Next, using the eigenmode associated with the smallest non-zero eigenvalue as a perturbation to an otherwise perfect mesh, a response analysis is carried out using the Riks method option provided in ABAQUS ${ }^{\circledR}$. This is done for a series of imperfection magnitudes. The eigenmodes provide the perturbation shape but not the absolute magnitude of perturbation. Thus, the imperfection magnitude must be specified by the user. In the present work, this is achieved as follows; as shown in Figure 3(b), the maximum amplitude of the lowest eigenmode (which occurs along the edge AD) is chosen such that the fiber misalignment angle $\phi$ is approximately in the range $0.05^{\circ} \sim 1^{\circ}$. Since $\lambda$ is known, $\delta$ is chosen such that $\phi$ assumes the intended value. After several runs corresponding to different values of $\phi$ are completed, the load maxima associated with the RF1 vs. LPF curves are plotted as a function of imperfection magnitude. Here, RF1 stands for the resultant compressive load of the microregion and LPF stands for load proportionality factor, which indicates the amount of generalized load applied to the microregion expressed as a fraction of the total load. Then, by extrapolation of the maximum load, the value corresponding to the perfect case (no imperfection) is obtained. The perfect case corresponds to perfectly straight fibers and this case yields an upper bound for the attainable load maximum.
The fiber (IM7) is assumed to be linearly elastic (see Table 1), and the matrix (3270 toughened epoxy) property within the laminate is evaluated from the $+45 /-45$ coupon test, which will be described in the next section. Thus, the in-situ elastic plastic matrix behavior is incorporated in the present analysis. The matrix is modeled as a J2 incremental flow theory solid with isotropic hardening.

The cases studied in this paper correspond to those from the experiments as reported in [Ahn and Waas (2001)] $]^{5}$. Thus, for each laminate, two different runs are performed, one at room temperature and one at elevated temperature. For each temperature, uniaxial and biaxial loading cases are investigated. In this manner, we have studied four different cases for each laminate type. Of course, in the quasi-isotropic case, there are four additional cases, since both the zero ply and the 45-degree ply are investigated. Tables of results corresponding to the above cases are as shown in Table 2 and Table 3 . The results obtained for different imperfection magnitudes are also shown in these tables.

\section{In-Situ Matrix Characterization}

To evaluate the material properties of the matrix within the laminate (in-situ matrix properties), $a( \pm 45)_{n s}$ coupon test (Figure 5) at room and high temperature was performed following the procedure of ASTM-D3518-76 [ASTM Standard, (1982)] $]^{8}$. The elastic properties of the lamina and the complete shear stress-shear strain behavior of an IM7/3270 in the principal material coordinate system were obtained from this test. The procedure used to generate the data consists of subjecting a $( \pm 45)_{n s}$ angle ply laminate to uniaxial compression and measuring the laminate strains $\varepsilon_{x x}$ and $\varepsilon_{y y}$ and the applied remote stress on the laminate. Note that, for this test, $\gamma_{x y}=\varepsilon_{x x}-\varepsilon_{y y}$. The data shown in Figure 6 from this test can be used to extract the complete nonlinear shear stress - shear strain response of the in-situ matrix (3270) as discussed below. We begin by assuming that the 3270 matrix material can be modeled as an elastic-plastic solid obeying the small strain $\mathrm{J} 2$ flow theory of plasticity [Lubliner, $(1998)]^{9}$. Then, from the elastic (linear) portion of the curve in Figure 6 , we first obtain the inplane lamina shear modulus $G_{12}$. In the lamina principal coordinates, we know that, 


\section{AIAA-2001-1640}

$$
\begin{aligned}
& \varepsilon_{11}=\varepsilon_{22}=\frac{\varepsilon_{x x}+\varepsilon_{y y}}{2} \\
& \gamma_{12}=2 \varepsilon_{12}=\varepsilon_{x x}-\varepsilon_{y y}
\end{aligned}
$$

And

$$
\begin{aligned}
& \sigma_{11}=\frac{\sigma_{x x}}{2} \\
& \sigma_{22}=\frac{\sigma_{x x}}{2} \\
& \tau_{12}=\frac{\sigma_{x x}}{2}
\end{aligned}
$$

Thus, using (1) and (2) above and the definitions of equivalent stress, $\bar{\sigma}$ and equivalent plastic strain increment, $d \bar{\varepsilon}^{p}$ [Lubliner, (1998)] 9 , the data in Figure 7 can be used to construct a plot of $\bar{\sigma}$ against $\bar{\varepsilon}^{p}$.

According to the $\sqrt{2}$ flow theory of plasticity with a Mises-Henky yield condition, the ratio of the increment of each plastic strain component to its corresponding deviatoric stress component remains constant, which is [Lubliner, (1998)]

$$
\frac{d \varepsilon_{i j}^{p}}{\hat{\sigma}_{i j}}=d \lambda
$$

Using (3), and the relation between $\bar{\sigma}$ and $d \bar{\varepsilon}^{p}$, the nonlinear portion of the shear stress $\left(\tau_{12}\right)$-shear strain $\left(\gamma_{12}\right)$ response curve for a single lamina can be extracted. The curve thus obtained for IM7/977-3 system is shown in Figure 8. The instantaneous slope of the curve in Figure 8 is the tangent shear modulus of the lamina, $G_{12}\left(\tau_{12}\right)$. Therefore, we next use the approximate Halpin-Tsai relations [Daniel and Ishai, (1994)] ${ }^{10}$, below, to extract the variation of the in-situ matrix shear modulus $G_{m}\left(\tau_{12}\right)$, by using $G_{m}\left(\tau_{12}\right)$,

$$
\begin{aligned}
& G_{m}=G_{12}\left(\frac{1+\xi_{2} \cdot \eta_{2} \cdot v_{f}}{1-\eta_{2} \cdot v_{f}}\right)^{-1} \\
& \eta_{2}=\frac{G_{12 f}-G_{m}}{G_{12 f}+\xi_{2} G_{m}}
\end{aligned}
$$

and $\eta_{2}=1$ for random packing of fibers. With $G_{m}\left(\tau_{12}\right)$ so obtained, the in-situ matrix shear stress-shear strain curve is as shown in Figure 9. In a similar manner, the in-situ uniaxial stressstrain curve in compression for the matrix is also obtained. This uniaxial response curve was used in the input data file for the micromechanics based finite element analysis carried out using
ABAQUS\&. This curve is also shown in Figure 9. The same procedure is applied to the high temperature case and the results obtained for the matrix stress-strain curves are shown in Figure 10.

\section{FEA Results and Interpretation}

A typical load response behavior of a microregion within a cross ply laminate model is shown in Figure 11 and a series of deformed plots of the microregion showing the initiation and propagation of damage in the form of kink banding is as shown in Figure 12. The numbers indicated in the plot of Figure 10 correspond to the series of deformation plots shown in Figure 12 . The microregion response follows a linear path up to point (1). Although local matrix yielding (in areas of the microregion near the cutout) is indicated prior to the attainment of point (2), the total integrity of this region is not affected much from the matrix yielding because, (1) the area of yielding is small compared to the overall size of the microregion and (2) the fiber rotation is small up to the point of maximum load (point (2)). Thus, the resultant reaction force (RF1) vs. LPF relation is linear up to the maximum load point, although this is not necessarily what could be expected in other similar cases; that is, in general the RF1 vs. LPF behavior is problem dependent. As loading increases, the fibers in the areas where the matrix has become "softer" start to rotate, resulting in a drop of the resultant reaction force (RF1) computed at the symmetry plane (indicated by point (3), in Figure 11). As deformation progresses, the region of matrix yielding (and corresponding fiber rotation) is expanding, propagating upward away from the areas near the cutout (until it reaches point (4)-see Figure 11 for the deformed configuration). Once the region expands away from the hole to an area where the effect of the stress gradient has diminished, there is no tendency for further propagation and thus the load assumes a fairly constant value (plateau load). After this point, deformation becomes stabilized (fiber rotation stops) and the band of kinked fibers starts to broaden in the $x$ direction without any further sudden drop in the reaction force (5)).

The scenario just described is quite typical of the response of the microregion for all the cases corresponding to the cross ply laminate as well as to the zero ply microregion within a quasi-isotropic laminate. The far-field load (or loads corresponding to biaxial tests) corresponding to point (2) is read off and tabulated in Table 1 for all the cross-ply laminate cases studied herein. This load corresponds to failure initiation. 
For the case of quasi-isotropic laminates (Figure 2), the responses look different for each lamina (zero ply and 45 ply). Again, the zero ply response is similar to that of the cross-ply model but the far field load at which kink banding initiates is different. The 45-degree ply is modeled in a manner that is similar to the zero ply microregion, but the microregion boundaries are taken to be along the material principal directions (In this case the 45 degree and 135 degree directions-see Figure 2). Again, displacement boundary conditions are enforced on the edges $A B, B C$ and $C D$, while edge $A D$ is subject to equivalent equilibrium nodal loads. As loading proceeds, the RF1 vs. LPF relation is very nearly linear (Figure 13 (a)) and shows no sign of leading to a load maximum preceding a sudden load drop. At the same time, the corresponding plots for the equivalent plastic strain $\varepsilon^{p}$. VS. LPF (Figure $13(\mathrm{~b})$, sampled at the location with coordinates $(0.025$ in., 0.276 in.)) shows that the matrix elements contained between two fibers along the 45-degree direction and close to the cutout undergo increasing amounts of shearing. As loading proceeds, more and more of the matrix elements undergo large amounts of shearing. Simultaneously, the RF1 vs. LPF plot for the zero ply microregion approaches a maximum load. Thus, the scenario is as follows; the zero ply reaches a maximum load, at which stage kink banding is about to initiate in this ply. At the same time, the integrity of the 45-degree ply is compromised due to the large amounts of plastic straining. Thus, the laminate has a "choice" in selecting the failure path that corresponds to the largest release of energy. As observed experimentally, a fiber/matrix interfacial crack is seen to dominate the failure within the 45 degree ply, but not without some incident kink banding in the zero plies. Thus, in these cases, the maximum load corresponds to the initiation of kink banding which then triggers the mode of fiber/matrix interfacial failure that is observed experimentally in the 45-degree plies. Clearly, we need to have an accurate knowledge and measurement of the critical fiber/matrix interfacial fracture toughness (or the in-situ matrix fracture toughness, since the crack meanders between the fiber matrix interface and along the matrix) to carry out a fracture mechanics based energy release rate analysis of the 45 degree ply to ensure that it is indeed the mode of failure for which the largest amount of energy is released.

An analysis that includes strain energy release rate computation is relegated to the future, but details of such an analysis in the context of double cantilever beam specimens is reported in Song and Waas [Song and Waas (1995)] ${ }^{11}$. For now, we observe the good agreement between the far-field load corresponding to the maximum load prediction and the experimentally measured failure loads as indicated in Table 2, especially for the case of small imperfection $\left(\phi=0.8^{\circ}\right)$. This lends confidence to our contention that zero ply kinking is the dominant and hence governing mode of failure initiation in notched quasi-isotropic laminates. Such a conclusion, based only on experimental results, has been reached earlier by several previous investigators-see for example, Soutis, Fleck and Smith $[(1991)]^{12}$ and Khamseh and Waas $[(1997)]^{13}$.

\section{Concluding Remarks}

The results of the present micromechanics based global-local finite element analysis shows that the fundamental failure mechanisms of a symmetric multidirectional laminate is kink band formation due to a structural instability of the fibers, especially for laminates containing plies aligned along the remote load directions (cross-ply and quasi-isotropic laminates). The cross-ply laminates have only 0 and 90-degree lamina, and the majority of load is carried by simple compression of these laminae. These laminae fail by fiber microbuckling, (on account of a gradually weakening matrix in shear), which in turn progresses to kink band formation due to fiber rotation, followed by band broadening and the triggering of failure in other plies.

For the quasi-isotropic laminate, the majority of the load is still carried by the zero ply lamina. However, the difference between this laminate and the cross ply laminate is the angled ply $\left(45^{\circ}\right.$ ply in this case). This $45^{\circ}$ ply acts as a "buffer zone" (lower stiffness, but better shear response). Based on the analysis result, it is possible to postulate that although the matrix layers between any two fibers and situated near the zone of high stress and strain gradient are undergoing excessive plastic deformation (implies the possibility of activating small cracks at the fiber/matrix interface or within the matrix) the integrity of the laminate is still controlled by the zero-plies. As soon as the zero ply reaches an instability limit, two possibilities are encountered. Either energy is released by the spreading of the kink band within the zero plies or through interfacial fiber/matrix failure within the now compromised 45-degree plies. The "winner" of this competition is governed 
by the fiber/matrix interfacial fracture toughness and/or the in-situ matrix fracture toughness compared against the zero ply kink band toughness (defined as the energy released per unit advancement of the kinked band). Clearly, in this case, the kink banding triggers the failure since until the zero ply undergoes a load drop, the co-existing 45-degree ply has no possibility of initiating the fiber/matrix interfacial failure. Thus, the failure load prediction based on the zero ply maximum loads provides a good agreement with the corresponding experimental data.

\section{Acknowledgments}

We are grateful for the partial support from the AFOSR and the University of Michigan for this work. This paper is based, in part on the Ph.D. thesis of the first author submitted and defended in the Aerospace Engineering Department, University of Michigan, in December 1999

\section{References}

1. Ashby M.F. and Jones, D., "Engineering Materials 2", Pergamon, 1994

2. Mathews, F. L. and Rawlings, R., "Composite Materials: Engineering and Science", Chapman and Hall, London, 1994

3. Waas, A. M., and Schultheisz, C. R. "Compressive failure in Composites, Part II", Progress in Aerospace Science, Vol.32, pp. 43 $-78,1995$.

4. Starnes, J., Rhodes, M.D., and Williams, J.G., "Effect of Impact Damage and Holes on the Compressive Strength of a Graphite/Epoxy Laminate", Nondestructive Evaluation and Flaw Criticality for Composite Materials, edited by R. B. Pipes, ASTM STP 696, pp. 145-171, 1979.

5. Junghyun, Ahn and A.M. Waas, "Failure Mechanisms of a multidirectional laminates at room and elevated temperature", to appear in AIAA Journal, 2001.

6. Junghyun Ahn and A. M. Waas Finite Element Model for Compressive Failure of Notched Uniply Composite Laminates under Remote Biaxial Loads: ASME Journal of Engineering Materials and Technology: Vol.121 July, 1999.

7. Lekhnitskii S., "Theory of Elasticity of an Anisotropic body", Text, Godden-Day, 1968.

8. "D 3410-75 Standard Test Method for Compressive Properties of Unidirectional or Cross-ply Fiber-Resin Composites", 1982, Annual Book of ASTM Standards, Part 36,
American Society for Testing and Materials, Philadelphia, PA, 1982, 872-880.

9. Jacob Lubliner, "Plasticity Theory", Text, Prentice Hall, 1998.

10. Isaac M. Daniel and Ori Ishai, "Engineering Mechanics of Composite Materials", Oxford University Press, New York, 1994.

11. S. J. Song and A. M. Waas, "An Energy Method based Model for Mixed Model Failure of Laminated Composites", AIAA Journal, vol. 33, No. 4, 739-745, 1995.

12. Soutis, C., Fleck, N. and Smith, F., "Failure Prediction Technique for Compression Loaded Carbon Fiber-Epoxy Laminate with an Open Hole", J. Composite Materials, 25, pp14761498, 1991

13. A. Khamseh and A. Waas, "Failure Mechanisms of Composite Plates with a Circular Hole under remote Biaxial Planar Compressive Loads", ASME J. Materials and Technology, vol. 119, pp56-64, 1997 


\section{Tables and Figures}

\begin{tabular}{|c|c|c|c|c|c|}
\hline Material & $\begin{array}{c}E_{11} \\
(M s i \\
)\end{array}$ & $\begin{array}{c}\mathrm{E}_{22} \\
\text { (Msi) }\end{array}$ & $\begin{array}{c}\mathrm{G}_{12} \\
\text { (Msi) }\end{array}$ & $v_{12}$ & $\begin{array}{l}\text { Thickn } \\
\text { ess (in) }\end{array}$ \\
\hline $\begin{array}{l}\text { IM7 I } \\
977-3 \\
\text { Epoxy }\end{array}$ & 23.5 & 1.21 & 0.72 & $\begin{array}{c}0.3 \\
0\end{array}$ & 0.0052 \\
\hline IM7 Fiber & 42 & & & $\begin{array}{c}0.2 \\
5\end{array}$ & $\begin{array}{c}2.756 \\
\text { E-04 }\end{array}$ \\
\hline $\begin{array}{l}977-3 \\
\text { Epoxy }\end{array}$ & 0.7 & & & $\begin{array}{c}0.3 \\
4\end{array}$ & $\begin{array}{c}2.444 \\
E-04\end{array}$ \\
\hline
\end{tabular}

Table 1 Zero ply material properties of the $\mathbf{4 8}$ ply graphite / 977- 3 epoxy composites

\begin{tabular}{|c|c|c|c|c|}
\hline & $\begin{array}{c}\text { Uniaxial } \\
(\mathbf{k s i}) \\
\left(25^{\circ} \mathrm{C}\right)\end{array}$ & $\begin{array}{c}\text { Uniaxial } \\
(\mathbf{k s i}) \\
\left(200^{\circ} \mathrm{C}\right)\end{array}$ & $\begin{array}{c}\text { Biaxial } \\
(\mathrm{ksi}) \\
\left(25^{\circ} \mathrm{C}\right)\end{array}$ & $\begin{array}{c}\text { Biaxial( } \\
\mathrm{ksi}) \\
(200 \\
\left.{ }^{\circ} \mathrm{C}\right)\end{array}$ \\
\hline Analysis & 62 & 30 & 67 & 35 \\
\hline$\phi \approx 0.8^{\circ}$ & 40 & 21 & 46 & 25 \\
\hline $\begin{array}{c}\text { Experime } \\
\mathrm{nt}\end{array}$ & 44 & 19 & 37 & 18 \\
\hline
\end{tabular}

\begin{tabular}{|c|c|c|c|c|}
\hline $\begin{array}{c}\text { Mesh } \\
\text { Used }\end{array}$ & $\begin{array}{c}\text { Dimensio } \\
\mathrm{ns} \\
\text { X length } \mathrm{x} \\
Y \text { length }\end{array}$ & $\begin{array}{c}\text { Maximu } \\
\mathrm{m} \\
\text { Imperfec } \\
\text { tion Size }\end{array}$ & $\begin{array}{c}\text { Maximum } \\
\text { Resultant } \\
\text { stress on } \\
\text { Microregio } \\
\mathrm{n}(\mathrm{Ksi})\end{array}$ & $\begin{array}{c}\text { Plateau } \\
\text { Stress } \\
\text { on } \\
\text { Microre } \\
\text { gion }\end{array}$ \\
\hline $\begin{array}{c}\text { Baseli } \\
\text { ne }\end{array}$ & $\begin{array}{c}300 \mathrm{~d}_{\mathrm{f}} \mathrm{x} \\
142 \mathrm{~d}_{\mathrm{f}}\end{array}$ & $1.81 \mathrm{~d}_{\mathrm{f}}$ & 37 & 29 \\
\hline $\begin{array}{c}\text { Mesh } \\
\text { A }\end{array}$ & $\begin{array}{c}375 \mathrm{~d}_{\mathrm{f}} \mathrm{x} \\
142 \mathrm{~d}_{\mathrm{f}}\end{array}$ & $1.81 \mathrm{~d}_{\mathrm{f}}$ & 37 & 28 \\
\hline $\begin{array}{c}\text { Mesh } \\
\text { B }\end{array}$ & $\begin{array}{c}300 \mathrm{~d}_{\mathrm{f}} \mathrm{x} \\
177 \mathrm{~d}_{\mathrm{f}}\end{array}$ & $1.81 \mathrm{~d}_{\mathrm{f}}$ & 37 & 27 \\
\hline $\begin{array}{c}\text { Mesh } \\
\mathrm{C}\end{array}$ & $\begin{array}{c}375 \mathrm{~d}_{\mathrm{f}} \mathrm{x} \\
177 \mathrm{~d}_{\mathrm{f}}\end{array}$ & $1.81 \mathrm{~d}_{\mathrm{f}}$ & 37 & 26 \\
\hline $\begin{array}{c}\text { Mesh } \\
\mathrm{D}\end{array}$ & $\begin{array}{c}450 \mathrm{~d}_{\mathrm{f}} \mathrm{x} \\
213 \mathrm{~d}_{\mathrm{f}}\end{array}$ & $1.81 \mathrm{~d}_{\mathrm{f}}$ & 37 & 29 \\
\hline
\end{tabular}

Table 4 Results of the mesh convergence with hole diameter 0.5 in.

Table 2 Cross-ply analysis results

\begin{tabular}{|c|c|c|c|c|}
\hline & $\begin{array}{c}\text { Uniaxia } \\
\text { I (ksi) } \\
\left(25^{\circ} \mathrm{C}\right)\end{array}$ & $\begin{array}{c}\text { Uniaxial } \\
(\mathrm{ksi}) \\
(200 \\
\left.{ }^{\circ} \mathrm{C}\right)\end{array}$ & $\begin{array}{c}\text { Biaxial } \\
(\mathrm{ksi}) \\
(25\end{array}$ & $\begin{array}{c}\text { Biaxial } \\
(\mathrm{ksi}) \\
(200\end{array}$ \\
\hline Analysis & 38 & 22 & 44 & 24 \\
\hline$\phi \approx 0.8^{\circ}$ & 27 & 15 & 34 & 18 \\
\hline $\begin{array}{c}\text { Experim } \\
\text { ent }\end{array}$ & 21 & 19 & 26 & 24 \\
\hline
\end{tabular}

Table 3 Quasi-Isotropic ply analysis results
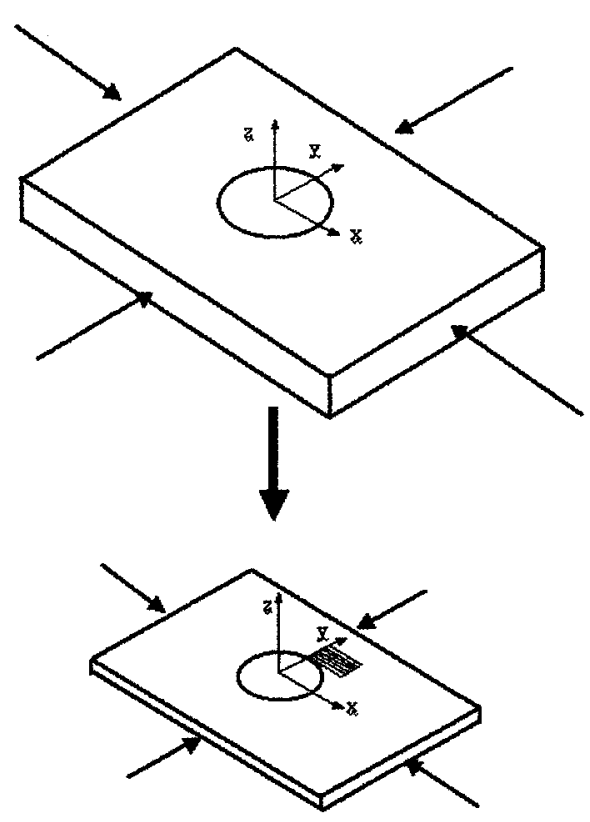

Figure 1 Cross-Ply Laminate Model 


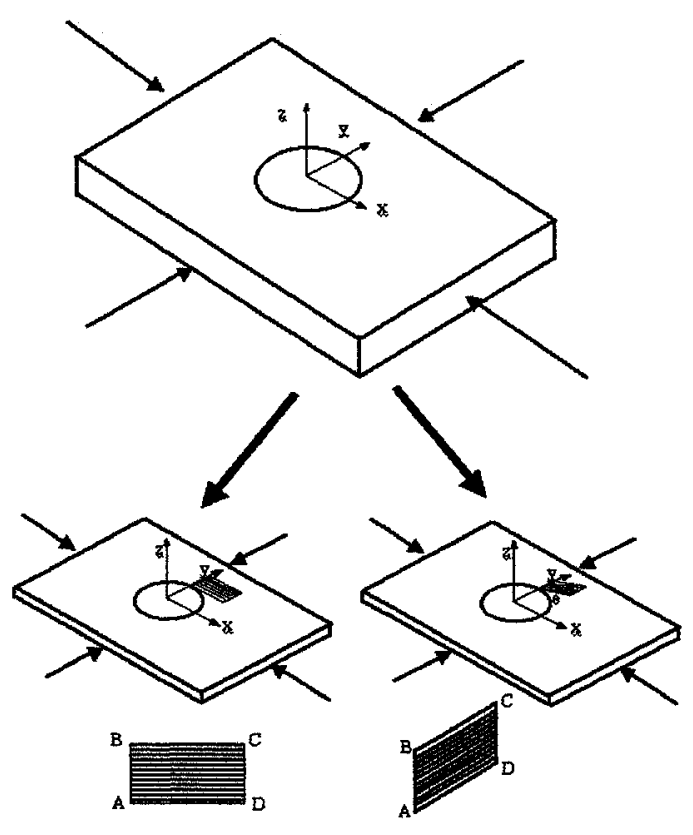

Figure 2 Quasi-Isotropic / Angle Ply Laminates Model

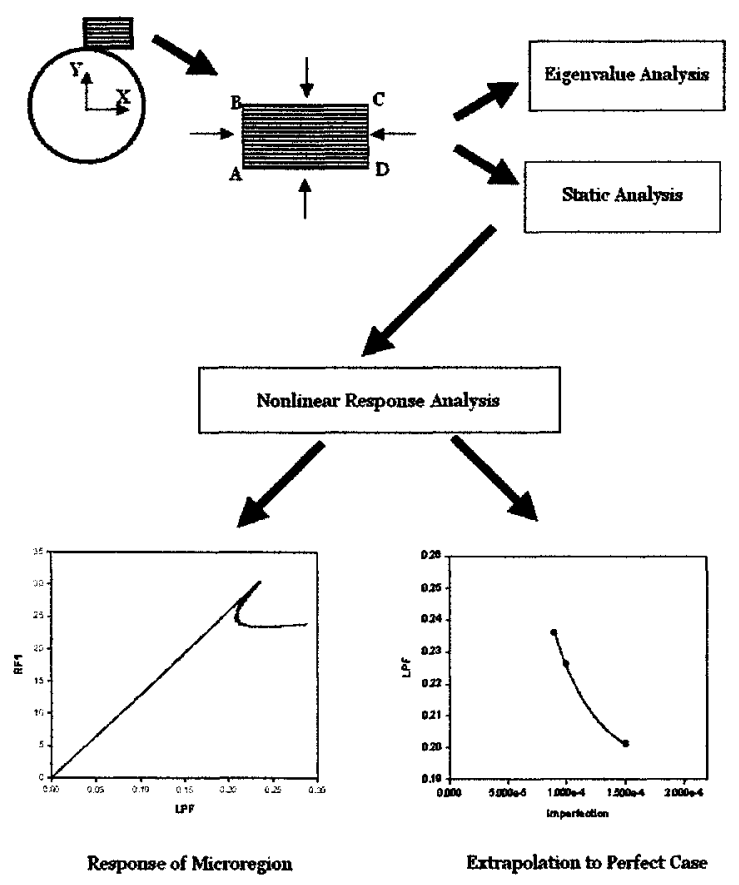

Figure 3(a) Imperfection Sensitivity Analysis Procedure
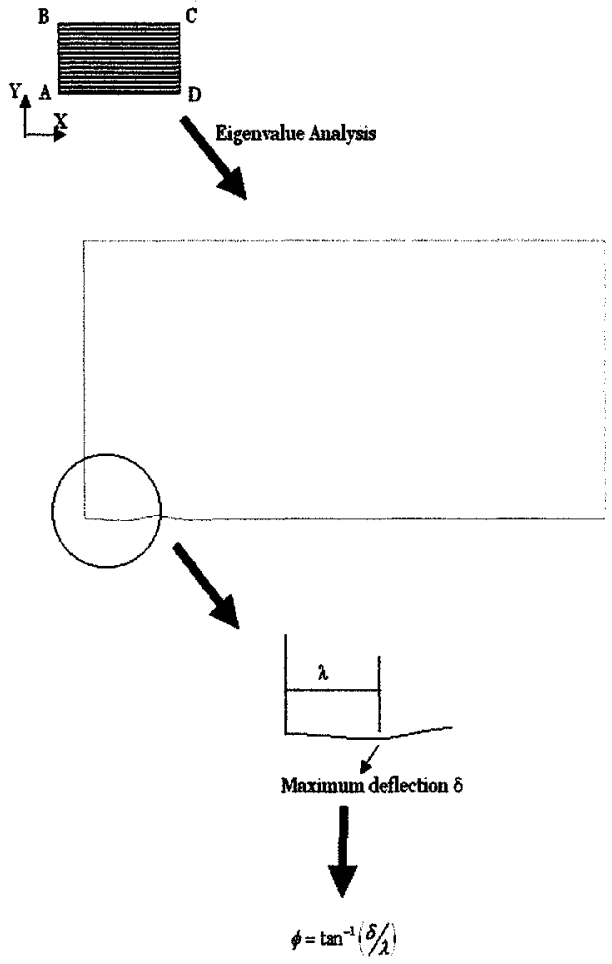

Figure 3(b) Imperfection definition based on $\phi$ (maximum deflection angle)

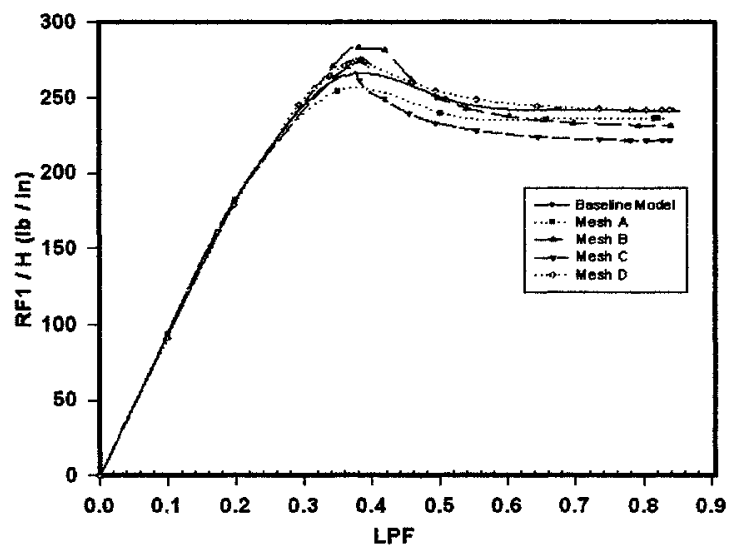

Figure 4 Effect of mesh size on load-shortening behavior of microregion 


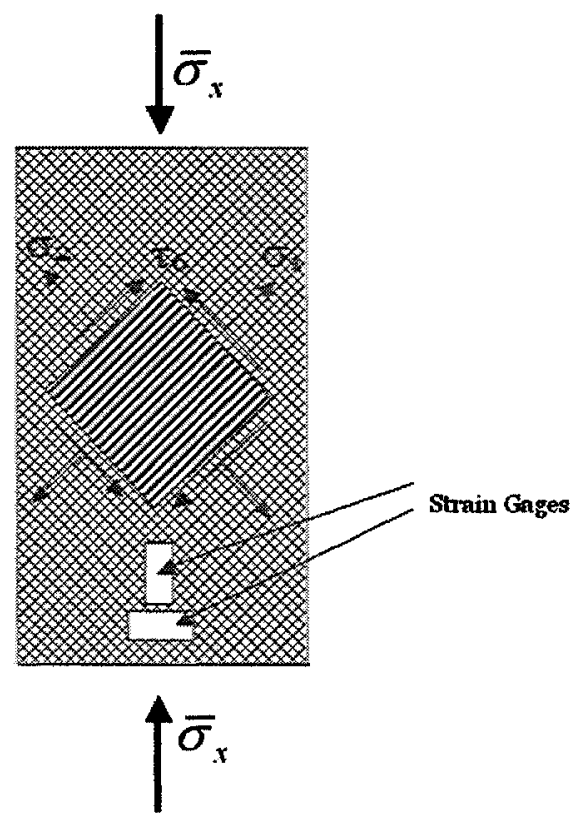

Figure 5. $+45 /-45$ coupon test of a specimen taken from the cross ply laminates

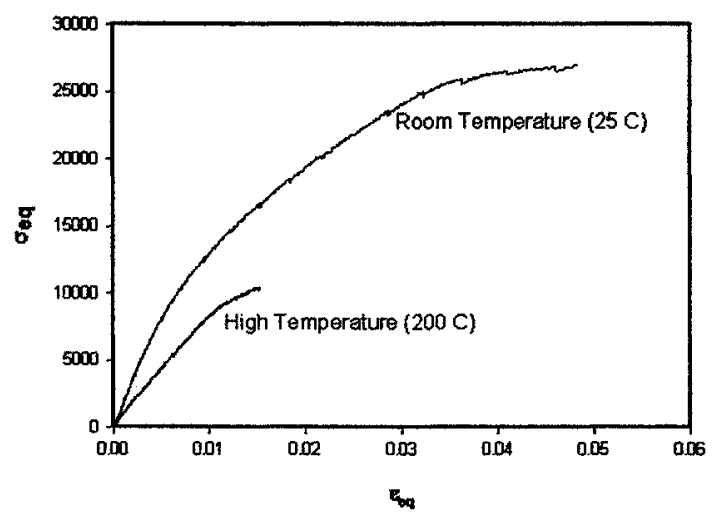

Figure 6. $+45 /-45$ compression experiment result

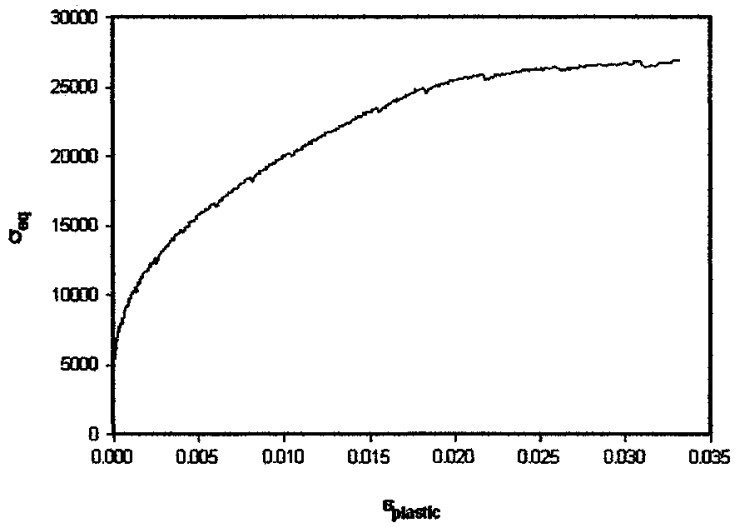

Figure 7. Equivalent stress vs. equivalent plastic strain (room temperature)

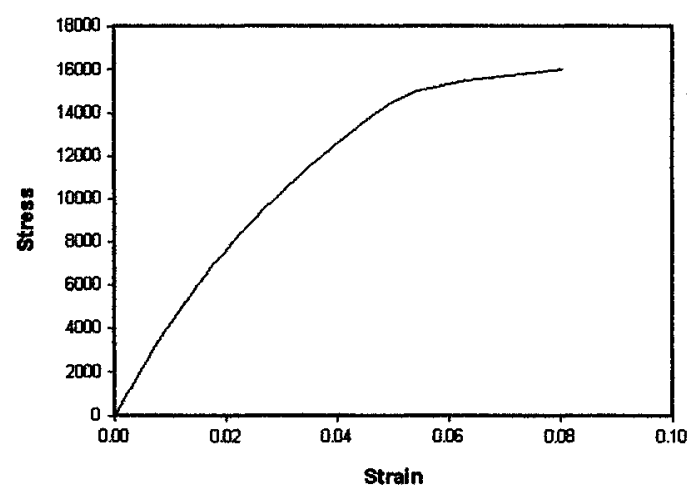

Figure 8 Shear Stress, $\tau_{12}$ vs. Shear Strain, $\gamma_{12}$ curve for IM7 / 3270 (room temperature) based on $\mathrm{J} 2$ Flow Theory of Plasticity and the data in Figure 7.

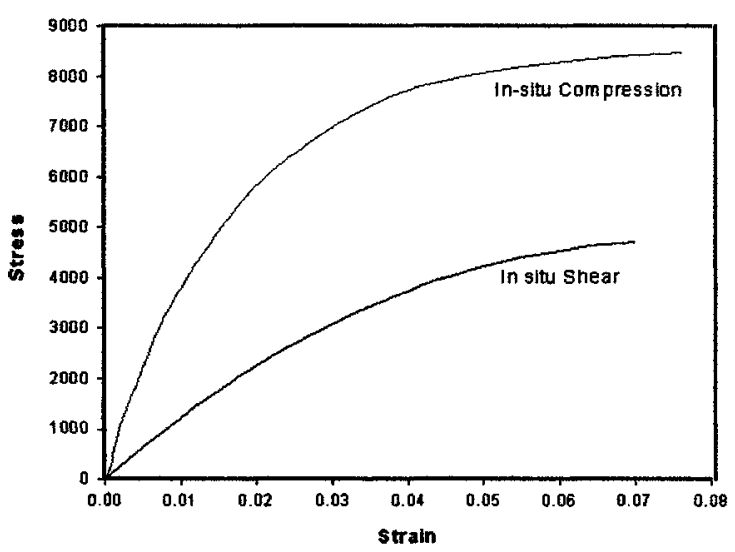

Figure 9. The in-situ Shear Stress vs. Shear Strain response of the matrix and the

deduced Uniaxial Stress vs. Uniaxial Strain Response of the Matrix (Room Temperature). 


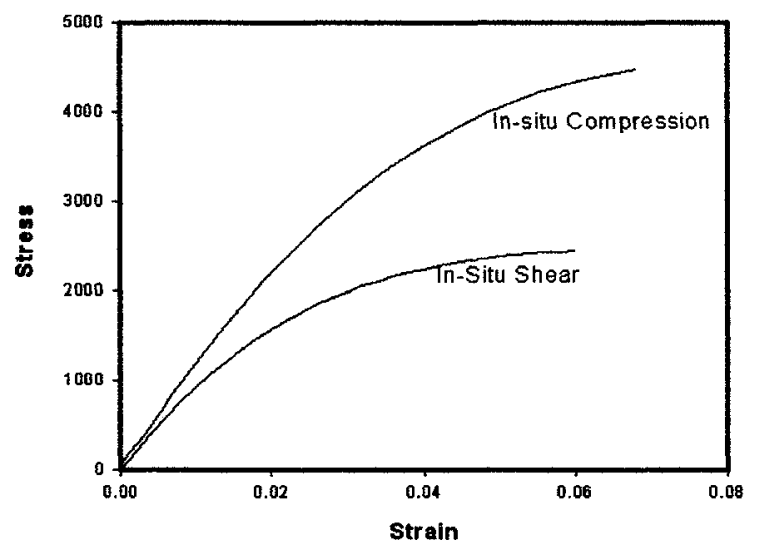

Figure 10. The in-situ Shear Stress vs. Shear Strain response of the matrix and the deduced Uniaxial Stress vs. Uniaxial Strain Response of the Matrix (High Temperature).

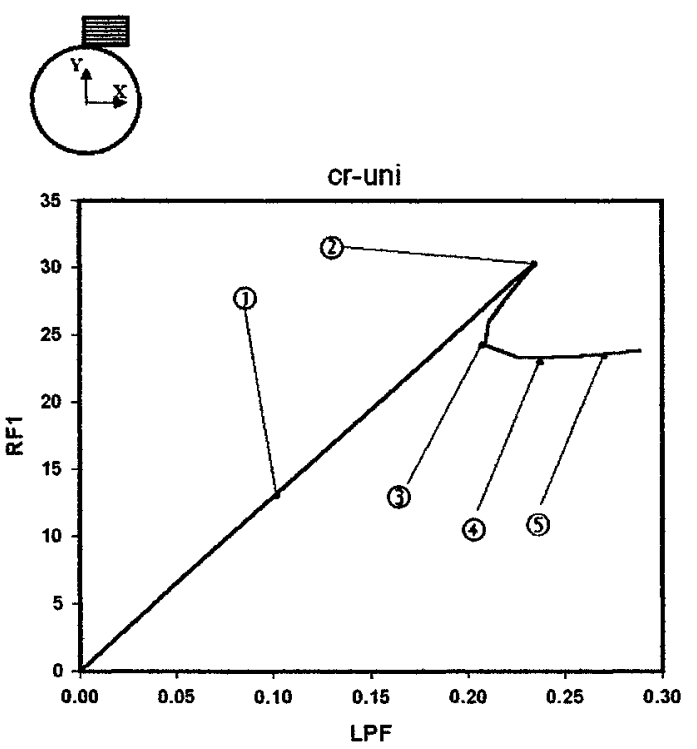

Figure 11. Response Plot of Typical Cross-Ply Analysis

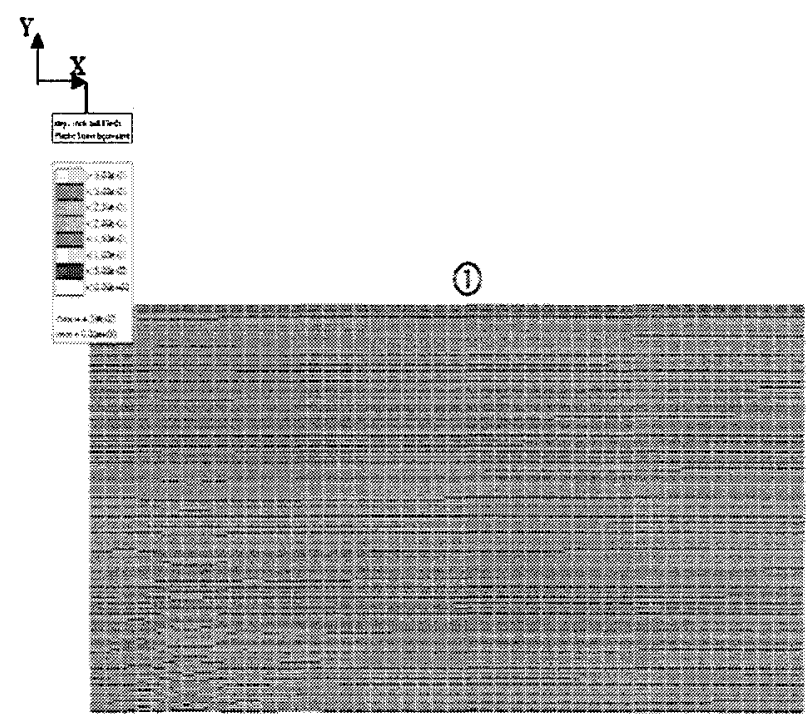

rots

(2)

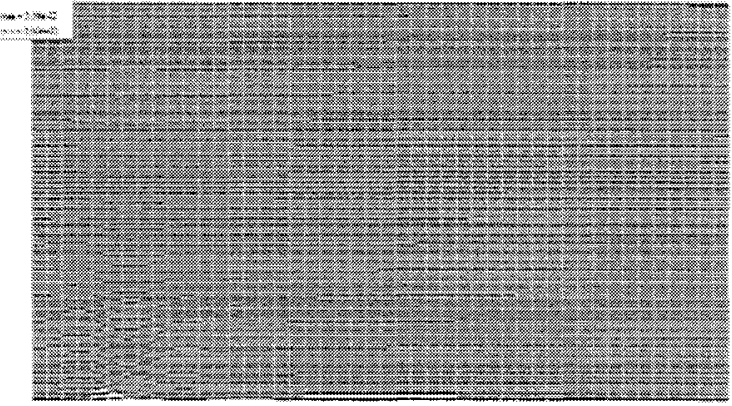



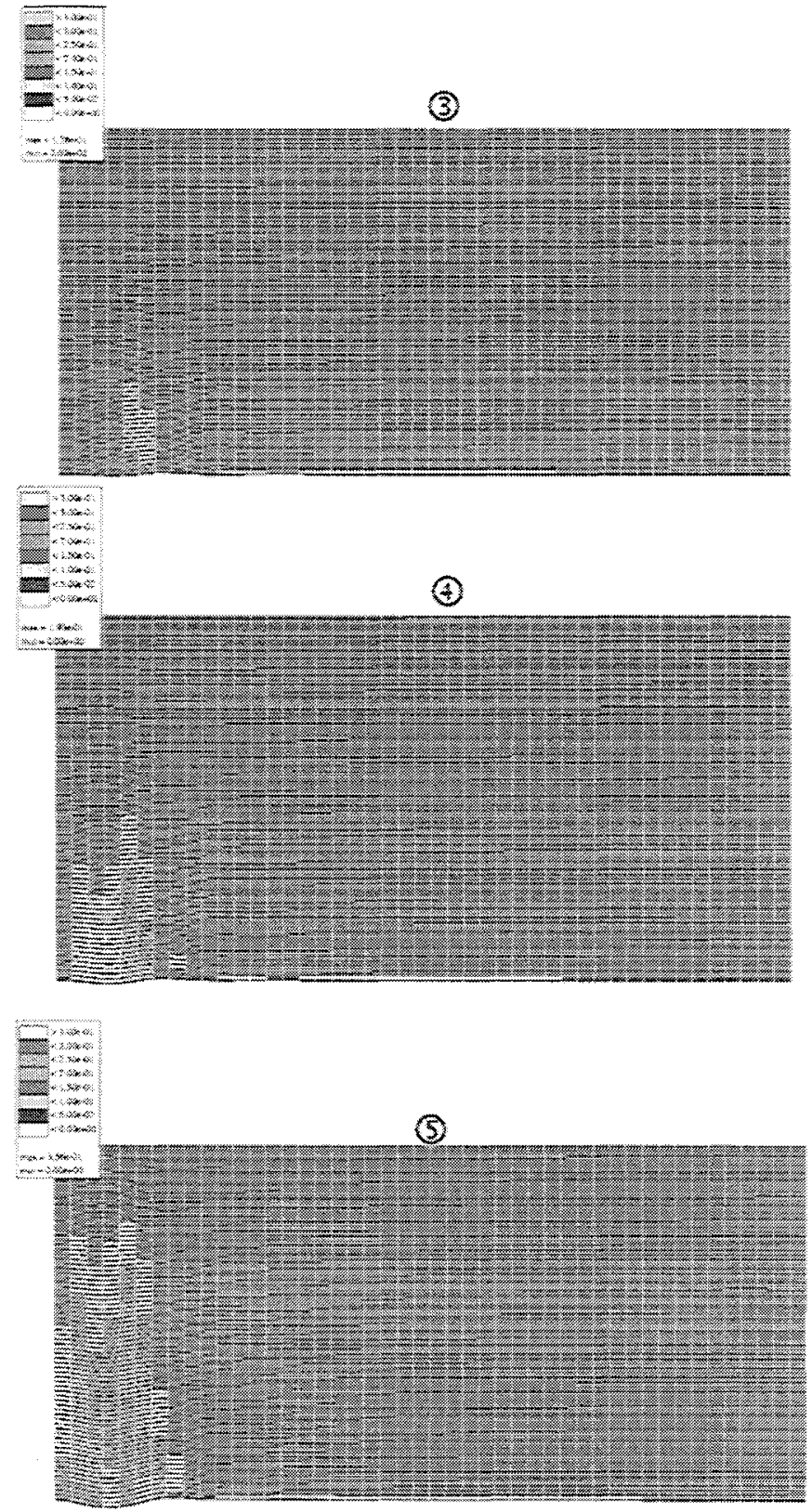

Figure 12 Deformed Microregion Shape

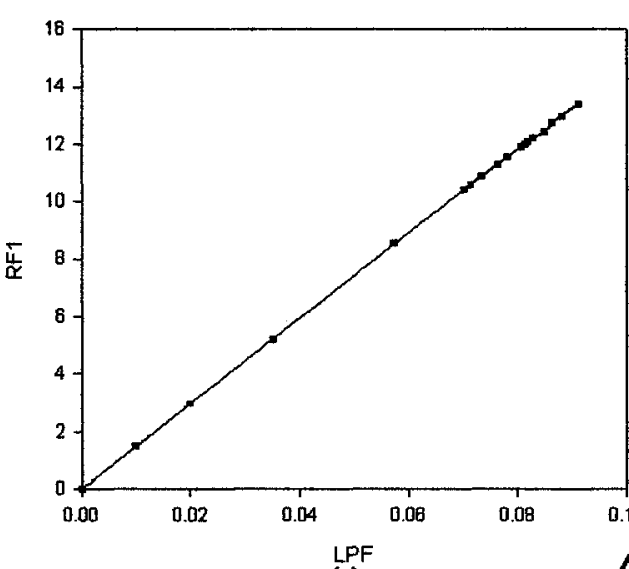

(a)

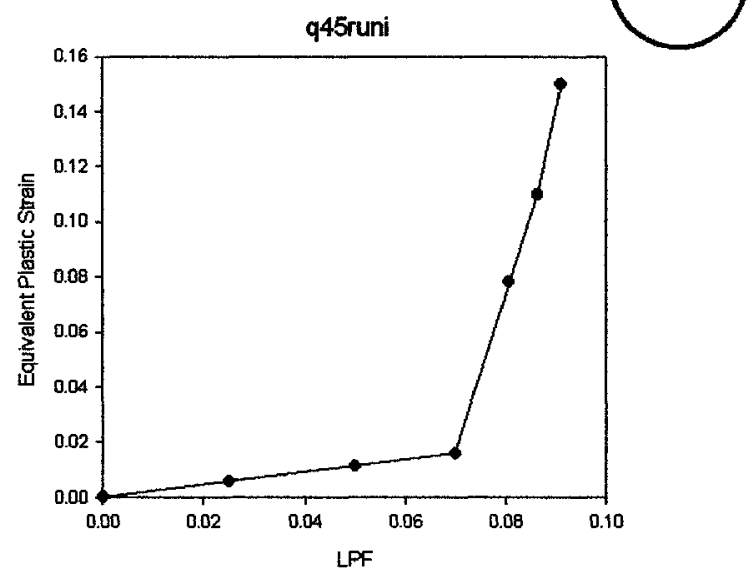

(b)

Figure $13.45^{\circ}$ ply response result for a quasi-isotropic laminate (The equivalent plastic strain is sampled at the point with coordinate $(0.021 \mathrm{in} ., 0.271 \mathrm{in})$. 